\section{El pediatra ante la discapacidad de niños y adolescentes}

\section{Pediatricians as health care providers for children and adolescents with disabilities.}

Los niños son el grupo social más vulnerable y los que tienen discapacidad se encuentran con una doble desventaja: la de ser niños y la de tener una discapacidad.

En la mayoría de las ocasiones, el pediatra es el primer contacto de salud de las personas con discapacidad. En nuestra formación profesional no se ha incluido el tema discapacidad como un problema social y sanitario prevalente, por lo que en la mayoría de los casos nos enfrentamos ante un panorama totalmente desconocido.

El Fondo de las Naciones Unidas para la Infancia sostiene que para garantizar la plena vigencia de los derechos de las niñas y niños con discapacidad, la información constituye un elemento clave, ya que la invisibilidad origina y perpetúa gran parte de las privaciones que sufren (UNICEF, 2013).

En México, la prevalencia de discapacidad es de 6 por ciento de la población; de éstos 1,200,000 son niños o adolescentes.

La discapacidad no se puede definir de forma rígida, "es un concepto que evoluciona y que resulta de la interacción de las personas con deficiencias y las barreras debidas a la actitud y el entorno que evitan su participación plena y efectiva en la sociedad en igualdad de condiciones con los demás."

La discapacidad forma parte de la condición humana y varía de acuerdo con las distintas épocas, culturas y sociedades. Histórica y afortunadamente, los modelos de la discapacidad han evolucionado caminando de la exclusión (exterminio) a la segregación y de la integración a la inclusión social.

La discapacidad ha atravesado el paradigma tradicional con una perspectiva religiosa, donde ésta era una expresión del mal, superando el infanticidio (Esparta) o esclavitud (Roma). Posteriormente, la discapacidad llegó a ser vista bajo un modelo médico-rehabilitador en el que se entendía a la diversidad funcional como enfermedad que requería recibir tratamiento a través de la institucionalización, y que muchas veces terminaba transformándose en una instancia de marginación y maltrato; este modelo consideraba a la discapacidad como un problema individual y asociado solamente a la salud.

En los años 60-70's del siglo XX nace el modelo social de la discapacidad, el cual rompe viejos conceptos y crea una revolución en esta materia, 
en el que se señala que no son las deficiencias individuales las raíz del problema, sino las limitaciones de la propia sociedad que no es capaz de asegurar las necesidades de las personas con discapacidad. Reconoce que mientras algunas personas tienen características físicas, sensoriales, intelectuales o psicológicas que pueden causar limitaciones funcionales, éstas no deben Ilevar a la discapacidad, a menos que la sociedad no tenga en cuenta las diferencias individuales.

El modelo social no niega que existan diferencias individuales que causan limitaciones, pero éstas no deben ser motivo de la exclusión de los individuos.

Dentro de las dificultades para su atención se pueden identificar factores asociados directamente a las personas con discapacidad: limitantes relacionadas con las características de los servicios de salud y factores relacionados con los profesionales de la salud; el más importante: el desconocimiento.

La sociedad tiene la responsabilidad de luchar por los derechos de las personas con discapacidad. Los médicos debemos comprometernos en buscar estrategias y aplicar adaptaciones en nuestra práctica clínica que promuevan no sólo los cuidados de salud, sino también la accesibilidad y equidad en la atención médica.

Este déficit en la atención médica y en el acceso a los servicios de salud de las personas con discapacidad es una situación preocupante, no sólo en nuestro país, sino en muchos de Latinoamérica; ya que sólo una de cada veinte recibe atención de un programa integral adecuado.

Uno de los problemas más importantes al que nos enfrentamos, es que los niños y adolescentes con discapacidad no tienen un pediatra de cabecera. No existe quien coordine a un equipo, por lo que los padres deben tomar las riendas, dirigir y clasificar diagnósticos, lo que lleva a un desgaste familiar y a una falta de atención integral de la persona, ya que no se ve a un niño completo, sino sólo fragmentos de él.

Los niños con discapacidad requieren la misma atención que el resto de los niños: hay que pesarlos, medirlos, vacunarlos, orientar a los padres acerca de los cambios que presentarán en las diferentes etapas de su infancia, de su alimentación, etc. Lamentablemente, esto se deja a un lado, no se les pesa y no se mide porque no caminan; no se les vacuna porque no van a la escuela o porque siempre están enfermos; no se les orienta sobre los cambios que manifestarán "porque son niños eternos", olvidamos tratarlos de acuerdo a su edad cronológica. Al margen de que tengan retraso psicomotor, cuadros genéticos o neurológicos complicados, deben ser tratados como niños.

A raíz de la falta de información y de participación de los pediatras en el seguimiento médico, los niños con discapacidad se atienden tarde, casi de cualquier padecimiento. "Si lloran, si se quejan, si son agresivos o irritables es por su condición", cualquier síntoma que tengan se atribuye a su discapacidad, con lo que se pierde un tiempo valioso que debería contribuir a su integración a la sociedad.

La exclusión, el prejuicio, el desconocimiento y la discriminación de las personas con discapacidad agravan su situación al vulnerar sus derechos fundamentales.

El pediatra debe estar consciente de que ante un niño con discapacidad, tiene el papel más importante: "es el director de la orquesta". Debemos dejar de ser espectadores de lo que realizan los subespecialistas y comprometernos con mejorar la atención que reciben. 
Qué necesita el pediatra

-Compromiso y responsabilidad ante grupos vulnerables.

-Conocimiento de la situación de salud de su área. Cuántas personas con discapacidad hay en el lugar donde labora y quién los ve.

-Conocer los servicios de referencia y mantener contacto directo con ellos para su atención oportuna, no solamente en el campo de la atención en rehabilitación médica, sino también en el campo de la educación, inclusión social, redes de apoyo de padres, así como de las especialidades médicas que requerirá para su atención y otras instancias fuera del sector que necesite esa persona.

-Aceptar la diversidad, evitando estereotipos y generalizaciones.

-Evitar la discriminación o exclusión inconsciente.

-Unirse a la "Revolución Inclusiva": hay que pensar de otro modo, para ver, sentir y actuar de forma diferente ante la discapacidad.

Un niño o niña con discapacidad no debe ser considerado como un problema; ser rescatado; recibir medidas caritativas ni ser receptores pasivos de atención y protección. Como pediatras y responsables del cuidado de la salud de los niños debemos exigir y reconocer a todos los niños, sin excepción, como miembros plenos de sus familias, comunidades y sociedades. Debemos erradicar las barreras de actitud y de comunicación que están a nuestro alcance y que impiden la realización plena de los derechos de la infancia, entre ellos el derecho a la salud incluyente.

La atención pediátrica inicial es una gran oportunidad de brindar conocimientos a la familia, detectar cuáles son sus necesidades y cómo darles solución, con lo cual su entorno se verá favorecido para brindar los medios para lograr su independencia y autodeterminación, facilitando su inclusión e integración social.

\section{Lecturas recomendadas}

1. United Nations Children's Fund (UNICEF). Estado Mundial de la Infancia (2013). Niñas y niños con discapacidad. Recuperado el 15 de diciembre del 2014 de: http://www.unicef.org/ lac/SOWC2013_fullreport_esp\%282\%29.pdf.

2. ¿Cómo pensamos de los niños/as con discapacidad? www.sap.org.ar/docs/congresos/2010/ ambulatoria/berridi_discapacidad.pdf

3. El abordaje de la discapacidad desde la atención primaria en salud edición a A. Vazquez $\mathrm{N}$. Cáceres. - 1a ed. Buenos Aires: Organización Panamericana de la Salud - OPS, 2008.

Dra. Karla Adney Flores-Arizmendi Médico Pediatra. Posgrado en manejo integral del síndrome de Down Médico Adscrito Clínica Down Instituto Nacional de Pediatría adneyss@gmail.com

Dra. Lidia del Carmen Gómez-Puente Médico pediatra Red Down México lidiagopu@gmail.com 